\title{
Severe lung injury following inhalation of nitric acid fumes
}

\author{
Lalitha V. Pillai, Dhananjay P. Ambike, Saifuddin Husainy, Sunil Vishwasrao, Satish Pataskar, \\ Suprashant D. Kulkarni
}

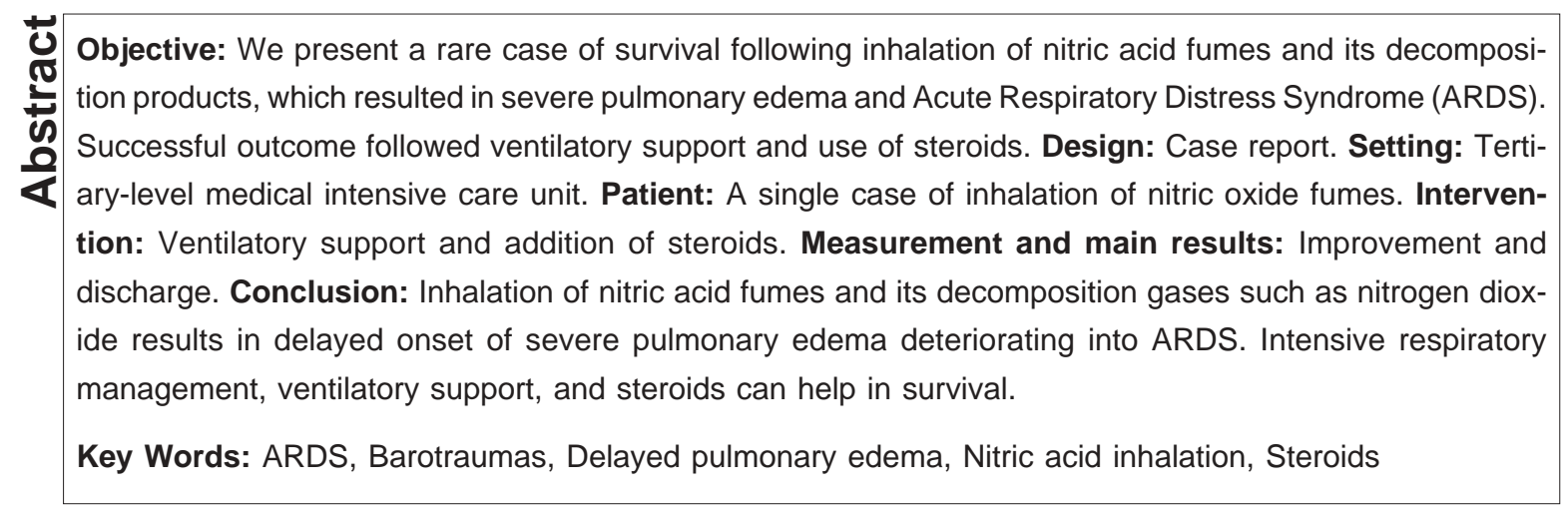

\section{Introduction}

Toxic effects on the lungs can be caused by inhalation of a wide range of gases and fumes. In the UK SWORD project, 1180 cases of inhalation of gases had been reported between 1990 and 1994. ${ }^{[1]}$ Among the common agents in this series were chlorine, nitrogen dioxide, and phosphorous. Inhalation injuries occur as a result of asphyxiation, local irritation, toxic absorption, or allergy. Irritant gases, when inhaled in high concentration, injure the respiratory tract by causing acute inflammationthe main site of injury depending on the solubility of the gases. More soluble gases exert maximal effect, more proximally in the respiratory tract. ${ }^{[2]}$

Nitric acid fumes and its decomposition gases such as oxides of nitrogen can cause devastating illness. ${ }^{[3-5]} \mathrm{We}$

\section{From:}

Department of Critical Caremedicine, Lokmanya hospitals, Chinchwad, Pune. India.

Correspondence:

Dr. Lalitha. V. Pillai, Department of Critical Care Medicine, Lokmanya Hospitals, Chinchwad, Pune-411033. E-mail: lalithapillai@rediffmail.com are presenting this rare case of survival following delayed onset of severe pulmonary edema, resulting from accidental inhalation of nitric acid fumes.

\section{Case History}

A 25-year-old male worker, recently employed (3 days back) in a metal industry, was brought to the ICU at 2 AM with a history of progressive cough and breathlessness, $8 \mathrm{~h}$ after inhalation of fumes at work.

His job involved cleaning aluminum components by immersing it in a covered bin containing nitric acid. Inadvertently, he put some mild steel parts in it. Eight hours later, at the end of the shift, when he opened the bin, there were fumes that he inhaled. This resulted in a bout of cough, but he was well enough to cycle $6 \mathrm{~km}$ to his home. As his cough and breathlessness increased in the night, he initially visited his general practitioner who then referred him to our hospital.

On arrival at $2.00 \mathrm{Am}$, he was conscious, well oriented, severely orthopneic with $P R=110 / \mathrm{min}, B P=114 / 70$ 
$\mathrm{mmHg}, \mathrm{RR}=40 / \mathrm{min}$, and $\mathrm{SpO}_{2}=80 \%$ (with venturimask- $\left.-\mathrm{FiO}_{2}=0.5\right)$. He had severe peripheral and central cyanosis. On auscultation, there were bilateral extensive rales, rest of the systemic examination was normal.

Laboratory investigations were as follows: $\mathrm{Hb}: 11.4 \mathrm{gm} /$ dl, white blood cell count (WBCs): $18000 \mathrm{cu} / \mathrm{mm}$, blood sugar: $122 \mathrm{mg} / \mathrm{dl}$, blood urea: $26 \mathrm{mg} / \mathrm{dl}$, creatinine: 1.1 $\mathrm{mg} / \mathrm{dl}$, serum bilirubin: $1.4 \mathrm{mg} / \mathrm{dl}$, SGOT: $31 \mathrm{U} / \mathrm{L}$, SGPT: $31 \mathrm{U} / \mathrm{L}$, serum alkaline phosphatase: $95 \mathrm{IU} / \mathrm{l}$, lactic acid: $14 \mathrm{mg} / \mathrm{dl}$,serum Na: $128 \mathrm{meq} / \mathrm{l}$, serum K: $3.4 \mathrm{meq} / \mathrm{l}$, and serum Cl: $92 \mathrm{meq} / \mathrm{l}$. ABG revealed $\mathrm{pH} 7.2, \mathrm{pCO}_{2} 49.8$ $\mathrm{mmHg}, \mathrm{PO}_{2} 48.9, \mathrm{HCO}_{3} 22.8 \mathrm{mmol} / \mathrm{L}$, and $\mathrm{SpO}_{2} 79.8 \%$. The chest X-ray was suggestive of pulmonary edema (Figure 1).

He was sedated, paralyzed, and mechanically ventilated on pressure controlled mode with low tidal volume maintaining safe plateau pressure and started on antibiotics and steroids. Five hours later, he was noted to have

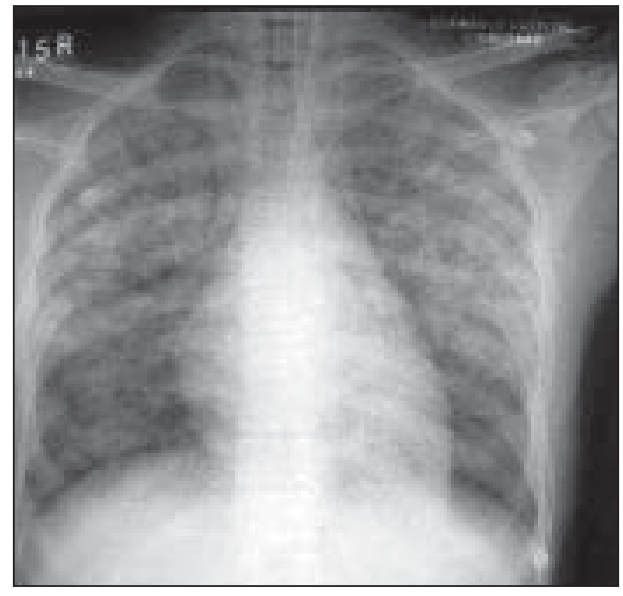

Figure 1: Pulmonary edema due to nitric acid fumes

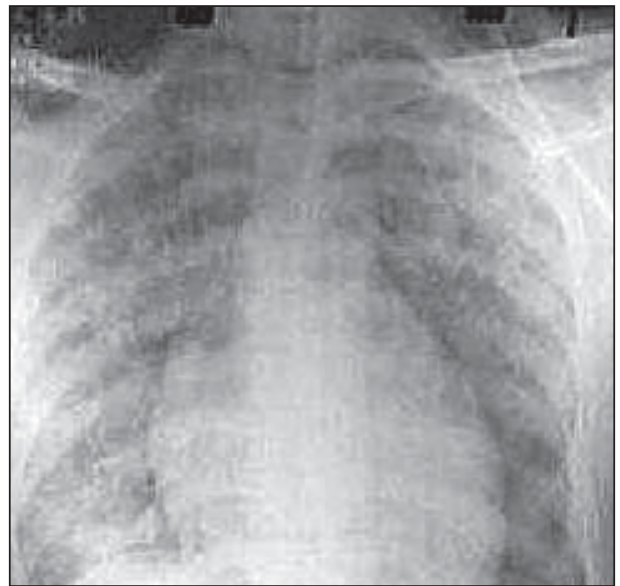

Figure 2: Bilateral infiltration with surgical and mediastinal emphysema surgical emphysema over the neck. Chest X-ray (Figure 2) confirmed surgical emphysema with mediastinal emphysema with no obvious pneumothorax. The urograffin meal ruled out esophageal leak. He needed to be ventilated with $\mathrm{FiO}_{2}>0.5$ for more than $48 \mathrm{~h}$. Lung injury score was 2.5 after $36 \mathrm{~h}$ of ventilation.

Two days later, he developed a right-sided pneumothorax. The WBC count was 20000/cumm. ABG showed $\mathrm{pH} 7.2, \mathrm{pCO}_{2} 65 \mathrm{mmHg}, \mathrm{pO}_{2} 66 \mathrm{mmHg}$, and $\mathrm{HCO}_{3} 25.8$ $\mathrm{mmol} / \mathrm{L}$ on $\mathrm{FiO}_{2}$ 1. An intercostal drain was placed on the right side. Bronchoscopy was done on the fifth day in view of right middle lobe collapse with further drop in saturation. It showed inflammed trachea and lower airways with thick secretions blocking the right middle lobe bronchus.

Over the next $72 \mathrm{~h}$, the patient made gradual recovery with chest $\mathrm{X}$-ray showing improvement. The patient could be weaned from the ventilator on the eighth day and extubated. On the ninth day HRCT-thorax revealed small pneumothorax on the apex of right lung, small mediastinal emphysema in superior mediastinal, prevascular space, and diffuse ground glass densities in both upper, lingual, and lower lobes, suggestive of resolving ARDS and bronchopneumonia.

He was shifted out of ICU on the 10th day of admission and discharged on the 11th day. At discharge PFT showed moderate restrictive lung disease [FVC - 55\% of predicted value and normal FEV1/ FVC ratio] and chest

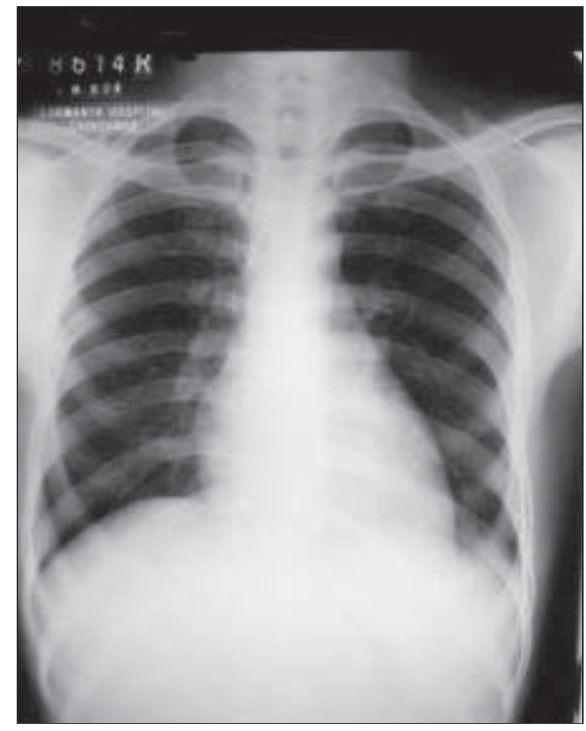

Figure 3: Chest x-ray one month later 
X-ray showed remarkable improvement. After 1 month, the follow-up X-ray (Figure 3) was normal and PFT showed mild restrictive lung disease. Subsequently, he was lost to follow up.

\section{Discussion}

Nitric acid is a highly corrosive and strong oxidant reacting explosively with many metals, organic compounds, and common construction materials such as mild steel, limestone, and mortar. ${ }^{[6]}$ These reactions result in release of nitric acid vapors and fumes of nitrogen dioxide. Toxic exposure to nitrogen dioxide has occurred in four circumstances: exposure to Silo gases, welding, combustion of nitrogen-containing materials, and spills of nitric acid. Exposure in chemical industry occurs when nitric acid spills and reacts with organic materials such as wood and paper. ${ }^{[2]}$

In our case the exposure occurred in a metal industry where nitric acid was used to clean aluminum components. Our patient was a new worker and decided to clean a mild steel part in the same way, not realizing the fact that nitric acid reacts with mild steel. Acid vapors and decomposition gases are both toxic. The acid vapor is usually colorless, whereas decomposition gases containing nitrogen dioxide is brown in color. It is an irritant and relatively insoluble in water; therefore, it tends to bypass upper airway without any warning irritation of the eyes or nasopharynx. ${ }^{[7]}$ In the moist mucoid environment of the lower respiratory tract, nitrogen dioxide dissolves and penetrates the bronchiolar and alveolar membranes generating free radicals and nitric and nitrous acid, and cause acute lung injury. ${ }^{[8]}$

Following the inhalation, seriousness of effects depend more on the highest concentration reached not on the duration of inhalation. This patient presented with life threatening pulmonary edema almost $8 \mathrm{~h}$ after the inhalation, before which he was well enough to cycle home $6 \mathrm{~km}$ and continued with normal activity. This delayed effect has been well described in almost all cases of nitric acid and nitrogen dioxide inhalation injury reports. ${ }^{[9,10]}$ Hajela et al. ${ }^{[8]}$ have reported three deaths owing to rapidly progressing pulmonary edema of delayed onset after inhalation of fumes from accidental nitric acid explosion in a pulp factory.

Smoke and inhalation injury has been reported to cause barotraumas, ${ }^{[7]}$ as it happened in our case. In spite of preventive measures of low tidal volume, safe plateau, and mean airway pressure, the patient developed mediastinal emphysema and pneumothorax. Use of lower partial pressure of oxygen, high frequency ventilation, and reducing the mean and peak airway pressure have been recommended. ${ }^{[7]}$ Cioffi et al.,., ${ }^{[11]}$ in a primate lung model, used high-frequency-flow-interrupted ventilation to demonstrate a reduced incidence of barotraumas and lung injury compared with conventional volume ventilation. Use of large-size endotracheal tubes to facilitate suctioning and bronchoscopy in inhalation injury cases has also been recommended. ${ }^{[7]}$ Bronchoscopy was both diagnostic of the inflammatory changes and also helped in clearing secretions in this case.

The electron microscope examination in the case study of Hajela et al. ${ }^{[8]}$ showed altered neutrophils and necrotic cells in alveolar capillaries. Immunohistochemistry revealed small and large serum proteins, including immunoglobulin $\mathrm{M}$, in the edema fluid and hyaline membranes. This could suggest that inhaled nitrogen dioxide causes direct microvascular injury, leading to increased permeability. Neutrophils and serum-derived mediators have been implicated in developing pulmonary edema owing to inhalation. Can this explain why steroids appear to help? Once absorbed, nitrite ions can also interact with vascular smooth muscles to cause vasodilatation and may react with hemoglobin to cause methemoglobinemia. In our case there was no clinical evidence such as brownish discoloration of blood to suggest methemoglobinemia and was not investigated further.

The spectrum of illness in nitric acid inhalation injury is variable and response severity is unpredictable. Survivors of high-level nitrogen dioxide exposure may experience a biphasic clinical response characterized by acute bronchospasm and laryngospasm and then development of pulmonary edema 8-24 h later. Between 10 and 31 days to a month later, patient can develop bronchiolitis obliterans. Most such cases resolve. As most of these incidents have been sporadic and accidental, follow up of the cases are not thorough. Like others, we could follow up our patients for only 1 month after discharge He was asymptomatic and had a normal chest X-ray. PFT showed mild restrictive pulmonary disease. Subsequent follow-up was lost. 
This case highlights the importance of preinduction training and education in workers. High-level exposure could have been prevented by appropriate education of workers and supervisory staff. We believe that the early use of steroids helped the survival and prevented the late sequel of broncholitis obliterans. This, along with good ventilatory support and timely interventions during episodes of barotraumas, contributed to the successful outcome.

\section{References}

1. Meredith S, McDonald JC. Work related -disease in United Kingdom 1989 - 1992: report on the SWORD project. Occup Med 1994;44:183.

2. Anthony Seaton: Occupational Lung Diseases, In: Anthony Seaton, Douglas Seaton, A. Gordon Leitch (Editors): Crofton and Douglas's Respiratory Diseases, $5^{\text {th }}$ edition. B Blackwell Science Ltd: 2000.p .1446.

3. Bur A, Wagner A, Roggla M, Berzlanovic A, Herkner H, Sterz F, et al. Fatal pulmonary edema after nitric acid inhalation. Resuscitation 1997;35:33-6.

4. Touze MD, Desjars P, Baron D, Tasseau F, Delajartre AY, Nicolas F. Collective acute poisoning by nitrous gases. Toxicol
Eur Res 1983;5:220-4.

5. Lehnert BE, Archuleta DC, ElliS T, Session WS, Lehnert NM, Gurley LR, et al. Lung injury following exposure of rats to relatively high mass concentrations of nitrogen dioxide. Toxicology 1994;89:239-77.

6. David L. Hinkamp; Properties of inorganic acids in Jeanne Mager Stellman, Michael McCann, Leon Warshaw, Carole Brabant et al (Eds) In: Encyclopedia of occupational Health and Safety, $4^{\text {th }}$ edition. international labor office: Geneva; 1998. p. 104.5-104.7.

7. Teofilo L, Lee-Chiong Jr: Smoke inhalation injury. Postgrad Med J 1999;105.

8. Hajela R, Janigan DT, Landrigan PL, Boudreau SF, Sebastian $S$. Fatal pulmonary edema due to nitric acid fume inhalation in three pulp-mill workers. Chest 1990;97:487-9.

9. Karlson-Stiber C, Hojer J, Sjoholm A, Bluhm G, Salmonson H. Nitrogen dioxide pneumonitis in ice hockey players. J Int Med 1996;239:451.

10. Sheperd LG. Confined-space accidents on the farm: the manure pit and the silo. Can J Emerg Med 1999;1:2

11. Cioffi WG, deLemos RA, Coalson JJ, Gerstmann DA, Pruitt BA Jr. Decreased pulmonary damage in primates with inhalation injury treated with high frequency ventilation. Ann Surg 1993;218:328-35 